\title{
Konsep Desain Jalur Pejalan Kaki Ramah Anak pada Rute Berbasis Footprint untuk Perjalanan Sekolah di Kecamatan Rungkut Surabaya
}

\author{
Alfie Fahruz Zubaidah dan Siti Nurlaela \\ Departemen Perencanaan Wilayah dan Kota, Fakultas Teknik Sipil Perencanaan dan Kebumian \\ Institut Teknologi Sepuluh Nopember (ITS) \\ J1. Arief Rahman Hakim, Surabaya 60111 \\ e-mail: nurlaela@urplan.its.ac.id
}

\begin{abstract}
Abstrak- Rencana Kota Layak Anak Surabaya 2019 diklasifikasikan menjadi 5 klaster pengembangan, diantaranya klaster lingkungan keluarga dan pengasuhan alternatif. Pada klaster ini dibahas topik mengenai penyediaan fasilitas pedestrian agar pejalan kaki merasa aman dan nyaman. Pada konteks "Kota Ramah Anak", terdapat indikator infrastruktur ramah anak. Pemerintah Kota Surabaya memiliki tujuan untuk dapat memberdayakan anak sebagai kota ramah anak. Jalan kaki merupakan moda transportasi aktif untuk memobilisasi anak, namun pengembangan trotoar ramah anak sebagai infrastruktur untuk perjalanan sekolah belum banyak ditemukan. Untuk itu diperlukan adanya pengembangan konsep desain trotoar yang aman dan nyaman bagi anak untuk mendukung pertumbuhan anak-anak secara aktif. Menyediakan infrastruktur pejalan kaki ramah anak dapat meningkatkan ketertarikan anak untuk mau berjalan di trotoar. Penelitian menggunakan Delphi untuk mengidentifikasi dan memvalidasi variabel, Importance Performance Analysis (IPA) untuk evaluasi variabel dan analisis Triangulasi untuk pengembangan konsep berdasarkan klasifikasi fungsi jalan, dan perangkat lunak Sketch $U p$ untuk visualisasi desain konsep sebagai luaran penelitian. Konsep desain trotoar ramah anak pada perjalanan sekolah berbasis jejak kaki atau footprint di Kecamatan Rungkut Surabaya ini terbagi dalam tiga kategori. Konsep tipe jalan kolektor I, konsep tipe jalan lokal II dan konsep tipe jalan lingkungan III. Ketiga konsep ini memiliki standar kenyamanan dan keamanan terendah. Konsep yang peneliti hasilkan diklasifikasikan menurut fungsi jalan dimana terdapat persamaan berupa fungsi kegiatan lahan di sekitarnya yang didominasi oleh perumahan dan permukiman.
\end{abstract}

Kata Kunci-Desain Ramah Anak, Footprint, Jalur Pejalan Kaki, Kriteria Desain.

\section{PENDAHULUAN}

$\mathrm{K}$ OTA Layak Anak (KLA) merupakan sistem pembangunan wilayah administrasi yang mengintegrasikan pemerintah, masyarakat, dan dunia usaha secara berkelanjutan dalam program kegiatan pemenuhan hak anak [1]. Memperhatikan perilaku anak melalui aktivitas yang sering dilakukan merupakan salah satu cara untuk mengetahui apa saja kebutuhan anak, sehingga tercipta pelayanan dan pemenuhan hak anak [2]. Anak akan berjalan kaki dalam melakukan kegiatan rutin seperti bersekolah dan bermain. Berjalan kaki berfungsi sebagai moda transportasi yang sering dilakukan anak dalam bermobilisasi. Pemerintah kota dapat mencoba mengubah perjalanan tersebut menjadi momen untuk belajar serta bermain serta membatasi kendaraan bermotor di daerahdaerah yang ramai dengan anak-anak [3]. Pejalan kaki merupakan salah satu kelompok yang seringkali menjadi korban kecelakaan. Setiap tahunnya, di dunia terdapat 1,35 juta orang meninggal disebabkan kecelakaan lalu lintas. Di Indonesia sendiri tercatat angka korban meninggal akibat kecelakaan pada tahun 2016 berjumlah 31.282 individu. Sejumlah $74 \%$ diantaranya adalah pengendara sepeda motor dan $16 \%$ berasal dari kelompok pejalan kaki [4]. Pada tahun 2017 saja, pejalan kaki menyumbang 16\% dari total korban kecelakaan, yang berarti setiap harinya 53 orang dari korban kecelakaan merupakan pejalan kaki [5]. Oleh karena itu, penyediaan sarana guna keselamatan pejalan kaki sangat penting.

Pemerintah Kota Surabaya telah melakukan Evaluasi KLA 2019 yang dibagi dalam 5 (lima) klaster. Pada klaster 2 mengenai lingkungan keluarga dan kebebasan terdapat poin tentang Pedestrian Aman dan Nyaman [6]. Penyediaan fasilitas pejalan kaki adalah bagian dari upaya pemenuhan infrastruktur. Pemerintah Kota Surabaya berkomitmen agar anak-anak mendapat hak pelayanan. Gagasan Kota Ramah Anak (KRA) diawali dengan penelitian mengenai Children's Perception of the Environment oleh Kevin Lynch 1971-1975 dalam rangka Growing Up In Cities (GUIC) dengan tujuan mendokumentasikan persepsi dan prioritas anak sebagai perbaikan kota. Lingkungan kota yang paling ideal bagi anak merupakan kota dengan komunitas yang kuat secara fisik, sosial, aturan, dan fasilitas pendidikan [7].

Menurut UNICEF Innocenti Research Centre dalam Innocenti Digest No.10/10/02:22, hak-hak anak dengan perwujudan penyediaan: a. akses pelayanan kesehatan, pendidikan, air bersih, sanitasi; b. kebijakan dan anggaran khusus untuk anak; c. lingkungan aman dan nyaman, sehingga anak berkembang, berekreasi, belajar, berinteraksi sosial, berkembang psikososial dan ekspresi budayanya; $d$. keseimbangan sosial, ekonomi, dan terlindungi dari pengaruh kerusakan lingkungan dan bencana alam; e. memberi perhatian khususnya bagi anak yang tinggal dan bekerja di jalan, eksploitasi seksual, hidup dengan kecacatan atau tanpa dukungan orang tua; dan f. adanya wadah bagi anak-anak untuk berperan membuatan keputusan pada kehidupan mereka.

Peraturan Menteri Perhubungan Nomor PM 16 Tahun 2016 menetapkan penerapan Rute Aman Selamat Sekolah (RASS) 
yaitu manajemen dan rekayasa lalu lintas, berupa penyediaan sarana dan prasarana angkutan dengan pengendalian lalu lintas dan penggunaan jaringan jalan menuju sekolah untuk menjamin rasa aman dan selamat. RASS di Indonesia mempunyai kriteria tersedianya prasarana dan sarana transportasi yang aman dan selamat, baik itu berupa prasarana dan sarana.

Berdasarkan hasil pengamatan di Kecamatan Rungkut Surabaya, tidak semua ruas jalan memiliki jalur pejalan kaki. Khususnya pada ruas jalan yang dekat dengan kawasan sekolah. Artinya, saat ini belum banyak dijumpai pengembangan jalur pedestrian ramah anak yang merupakan bagian dari upaya mewujudkan infrastruktur ramah anak khususnya pada perjalanan sekolah. Karakteristik anak sekolah dasar di Kecamatan Rungkut yang lokasi rumahnya berada pada 500 meter dari sekolah sebagian besar bermobilisasi dengan moda berjalan kaki dan/atau bersepeda melewati jalur yang dianggap aman dan nyaman. Rata-rata anak yang rumahnya pada jarak tempuh $\pm 400-450$ meter dari sekolah memilih untuk berjalan kaki. Berdasarkan pengamatan diketahui bahwa selama ini perjalanan anak ke sekolah adalah melalui rute hasil jejak tapak yang dirasa aman untuk menuju ke sekolah. Rute tersebut dalam penelitian ini disebut sebagai footprint. Istilah footprint yaitu pemilihan ruas jalan yang diamati merupakan jalur yang biasa dilalui oleh anak sekolah. Rute berbasis footprint merupakan hasil pilihan rute yang dikenali dan paling efisien dilalui oleh pengguna jalan menurut hasil observasi di wilayah penelitian. Rute jalan tersebut dijadikan sebagai koridor prioritas penataan dalam penelitian untuk mengetahui apakah telah memenuhi pelayanan jalur pejalan kaki yang ramah anak dengan tingkat aman, nyaman, dan selamat atau belum.

Menurut penelitian Marearna Andreou tahun 2010 dalam jurnal "Planning for Pedestrian Safety Around Schools" menyebutkan terdapat 4 (empat) prinsip keselamatan pejalan kaki sekitar sekolah salah satunya adalah jalan setapak. Keberadaan jalan setapak sebagai pendukung moda berjalan kaki bagi anak sekolah yang harus diperhatikan [8]. Moda transportasi yang paling dianjurkan bagi anak usia TK - SD adalah berjalan kaki, khususnya jika tempat tinggal mereka dengan sekolah berada dalam radius kurang dari satu kilometer. Menurut Ideal Neighborhood Unit, sekolah tingkat dasar adalah pusat unit lingkungan hunian dan kemampuan jarak tempuh berjalan kaki usia anak. Jalur pejalan kaki ramah anak yang menjadi prioritas adalah jalur antar rumah dan sekolah [9]-[10]. Penelitian-penelitian sebelumnya menjelaskan bagaimana penyediaan jalur pejalan kaki yang aman dan nyaman, sehingga penting dilakukan penelitian lanjutan yang membahas kriteria penyediaan jalur pejalan kaki ramah anak yang dapat mendukung pelayanan perjalanan yang aman dan nyaman. Penelitian ini bertujuan merumuskan konsep penyediaan jalur pedestrian ramah anak yang dapat memberikan rasa aman dan nyaman saat melakukan perjalanan sekolah. Pentingnya penelitian ini dilakukan untuk membahas dan meneliti jalur pejalan kaki ramah anak agar mendukung pelayanan kebutuhan anak dalam melakukan perjalanan yang aman dan nyaman pada rute berbasis footprint untuk perjalanan sekolah sesuai kondisi karakteristik wilayah di Kecamatan Rungkut Kota Surabaya.
Tabel 1.

Indikator dan Variabel Hasil Sintesa Pustaka

\begin{tabular}{cc}
\hline \hline Indikator & Variabel \\
\hline Keselamatan & Jalur pejalan kaki/ Trotoar \\
& Penyeberangan pejalan kaki \\
& Pemisah lalu lintas lokal \\
& Rambu lalu lintas \\
& Pembatasan kecepatan kendaraan \\
Keamanan & Lampu penerangan \\
Kenyamanan & Pelindung/ Peneduh \\
& Tempat sampah \\
& Kondisi perkerasan trotoar \\
& Kran siap minum \\
Kemudahan & Lebar ruang berjalan kaki \\
& Keterhubungan/ Konektivitas \\
Daya Tarik & Elemen keindahan \\
& Sarana bermain \\
Humanis & Ubin pemandu \\
& Petunjuk jalan \\
& Jalur yang melandai \\
\hline \hline
\end{tabular}

\section{METODE PENELITIAN}

\section{A. Pendekatan Penelitian}

Riset ini menggunakan pendekatan rasionalistik, yaitu melihat sebuah kebenaran berasal dari fakta dan realita di lapangan, kemudian ilmu yang telah dibangun berdasarkan fakta empiris tersebut didukung dengan landasan teori dari literatur serta pemikiran melalui argumentasi suatu bagian dari hasil konstruksi berpikir [11]. Pendekatan ini dipilih karena dapat menyesuaikan dengan tujuan yang ingin peneliti capai berupa perumusan konsep desain jalur pedestrian yang ideal bagi anak terutama di rute berbasis jejak kaki (footprint) untuk perjalanan sekolah di Kecamatan Rungkut Surabaya menurut variabel yang disepakati oleh para ahli dan telah dinilai tingkat kepentingan dan kinerja tiap variabel oleh pengguna jalan.

\section{B. Jenis Penelitian}

Jenis penelitian deskriptif berfokus pada permasalahan penelitian [12]. Penelitian eksploratif merupakan penelitian yang menggali sebab-sebab terjadinya sesuatu. Tujuan dari penelitian yang bersifat eksploratif adalah berusaha untuk menggali pengetahuan baru dan mengetahui suatu permasalahan yang sedang terjadi [13]. Penelitian kuantitatif yaitu penilaian variabel. Penelitian kualitatif berupa serangkaian analisis deskriptif hingga perumusan konsep.

\section{Indikator dan Variabel}

Objek penelitian dalam studi ini atau variabel diperoleh dari tinjauan pustaka materi yang berkaitan dengan sasaran penelitian. Variabel tersebut berasal dari turunan indikator yang akan dipelajari / diamati. Menurut [14], perancangan memperhatikan kriteria desain terkait keselamatan, kondisi menyenangkan, kenyamanan dan daya tarik. Menurut [3] dalam Jakarta NMT Vision and Design Guideline, terdapat elemen yang membuat ruang lengkap, aman, nyaman, dan humanis. Menurut [15] dalam bukunya berjudul "Pedestrian Ways dalam Perancangan Kota", terdapat aspek yang harus diperhatikan dalam penyediaan ruang pejalan kaki yaitu keamanan (safety) 
dan kenyamanan (comfort). Penjelasan lebih lanjut mengenai variabel penelitian yang digunakan peneliti pada Tabel 1 . berdasarkan kebutuhan sasaran penelitian merupakan hasil dari sintesa kajian pustaka.

\section{Populasi dan Sampel}

Terdapat 2 jenis sampel responden dalam penelitian ini yaitu responden pakar (stakeholders expert) dan responden pengguna jalan (pelaku pejalan kaki). Responden pakar terpilih dengan teknik Purposive Sampling meliputi: Pemerintah Kota Surabaya melalui Dinas Pengendalian Kependudukan, Pemberdayaan Perempuan dan Perlindungan Anak dan Pemerintah Kecamatan Rungkut, Pengelola/Pelaksana melalui Dinas PU Bina Marga dan Pematusan Surabaya, Akademisi dari Dosen PWK ITS dan NGO dari Eco Transport Indonesia. Responden pengguna jalan dengan teknik Purposive dan Accidental Sampling terpilih dengan jumlah 98 responden pejalan kaki. Responden pejalan kaki memiliki kriteria yaitu warga (siswa usia anak sekolah dasar dan orangtua/guru siswa) yang berdomisili di Kecamatan Rungkut Surabaya (khususnya Kelurahan Kalirungkut dan sekitarnya) dan rutin/sesekali pernah berjalan kaki melewati Jl. Rungkut Puskesmas, Jl. Rungkut Asri Utara I, dan/ atau sekitarnya.

\section{E. Metode Pengumpulan Data}

Riset ini menggunakan kedua metode pengumpulan data primer dan sekunder. Data primer perlu adanya pengamatan di ruas wilayah penelitian di Kecamatan Rungkut Surabaya, wawancara mendalam kepada stakeholder pakar berdasarkan tingkat kepentingan dan pengaruhnya, dan kuesioner/angket pertanyaan terkait data yang diteliti. Sementara itu pengumpulan data mengkompilasi data dari sumber pustaka, data instansi, maupun dokumen perencanaan terkait penelitian.

\section{F. Teknik Analisis Data}

Analisis deskriptif kualitatif untuk analisa variabel-variabel dari hasil tinjauan pustaka dengan kondisi eksisting wilayah penelitian. Hasil analisis mendapatkan 6 indikator dengan total 17 variabel kriteria jalur pejalan kaki yang aman dan nyaman bagi anak dalam perjalanannya ke sekolah. Temuan tersebut dilanjutkan untuk proses analisis Delphi. Analisis Delphi dilakukan dengan wawancara kepada stakeholder expert untuk mendapatkan kesepakatan para ahli dalam memvalidasi variabel-variabel penentu jalur pejalan kaki pada rute berbasis jejak kaki yang menuntun anak dalam perjalannya ke sekolah. Analisis Importance Performance Analysis (IPA) berguna dalam penilaian tingkat kepentingan (harapan) dan tingkat kinerja (performa) atribut variabel yang menentukan keramahan rute jejak kaki anak berdasarkan pendapat dari pengguna ruas jalan penelitian dengan menggunakan software IBM SPSS Statistics 24. Hasil analisis Importance Performance Analysis (IPA) menunjukkan variabel prioritas berdasarkan tingkat kepentingan dan harapan dari pengguna jalan di wilayah penelitian. Analisis Triangulasi dalam penelitian ini digunakan untuk merumuskan konsep desain jalur pedestrian yang aman dan nyaman bagi anak sekolah di Kecamatan Rungkut Surabaya. Konsep dari analisis Delphi akan ditampilkan dalam bentuk ilustrasi visual menggunakan alat bantu perangkat lunak Sketch Up.

\section{HASIL DAN DISKUSI}

\section{A. Gambaran Umum Wilayah Penelitian}

Batas wilayah penelitian ini terletak di Kecamatan Rungkut Kota Surabaya. Penelitian ini dibagi menjadi 3 segmen pengamatan. Penentuan segmen pengamatan berdasarkan penetapan ketentuan: 1. Wilayah buffer dari lokasi Sekolah Dasar sebagai titik asal (point of origin) dengan jarak beradius pelayanan pendidikan selebar 500 meter dari lokasi permukiman sebagai titik tujuan (point of destination). 2. Wilayah penelitian merupakan ruas jalan sebagai jalur tapak kaki yang sering dilalui oleh anak sekolah dalam melakukan perjalanan sekolahnya. 3. Wilayah penelitian terdiri dari minimal dua klasifikasi fungsi jalan dan dapat mewakili gambaran dalam satu kecamatan secara umum. Hasil penentuan didapatkan segmen pengamatan yang berada pada ruas Jalan Rungkut Puskesmas dengan fungsi jalan kolektor sekunder, Jalan Rungkut Asri Utara I dengan fungsi jalan lokal, dan Jalan Rungkut Lor IX dengan fungsi jalan lingkungan. Dalam segmen penelitian terdapat 2 sekolah dasar yaitu SDN Kalirungkut I/264 di Jalan Rungkut Puskesmas dan SD Yamastho Surabaya di Jalan Rungkut Lor

Karakteristik penggunaan lahan di sekitar wilayah penelitian yaitu perumahan dan permukiman, fasilitas pendidikan (SD Yamastho dan SDN Kalirungkut I/264), fasilitas kesehatan (Puskesmas Rungkut), kantor pemerintah Kecamatan Rungkut dan Kelurahan Kalirungkut, KUA Kecamatan Rungkut, pasar rakyat Soponyono Rungkut, dan perdagangan jasa berupa pertokoan deret serta dekat dengan pusat perbelanjaan Transmart Rungkut.

Jumlah penduduk di Kelurahan Kalirungkut Tahun 2018 ada 23.659 jiwa dan luas wilayah administrasinya 258,4 Ha. Kepadatan penduduk Kalirungkut Tahun 2018 adalah 91,70 Jiwa/Ha. Sesuai dengan struktur kota, terdapat pembagian tingkat kepadatan penduduk yaitu tinggi, sedang dan rendah. Tingkat kepadatan rendah jika besar kepadatan penduduk $<150$ Jiwa/Ha [16]. Dengan demikian, Kelurahan Kalirungkut memiliki tingkat kepadatan penduduk rendah yang menempati angka 91,70 Jiwa/Ha. Komposisi penduduk tingkat usia sekolah dasar di Kalirungkut adalah 4.130 jiwa, artinya 18\% dari total penduduk berupa anak-anak (usia sekolah dasar). Penduduk setempat mayoritas beragama Islam. Terdapat Kampung Kue yang terletak di Jl. Rungkut Lor II. 


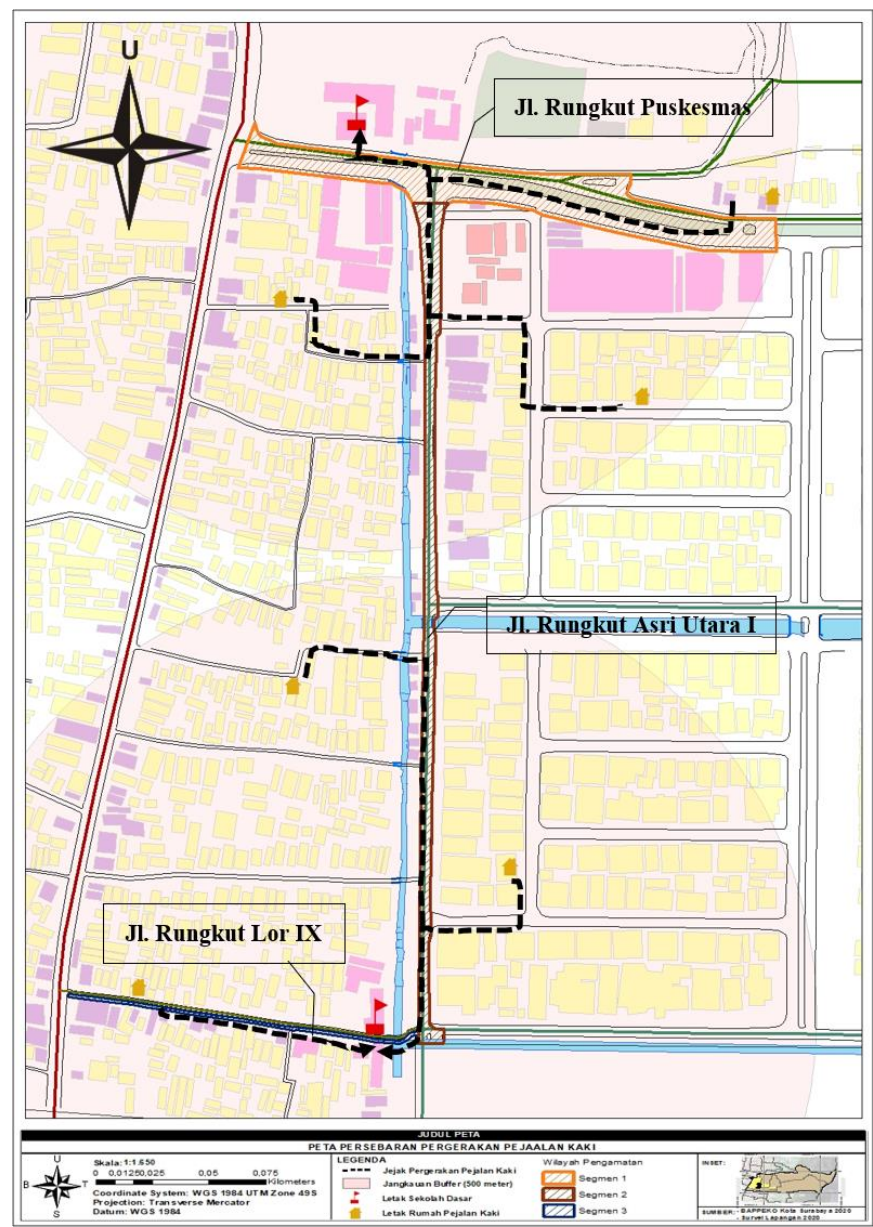

Gambar 1. Peta Persebaran Pergerakan Pejalan Kaki Anak dalam Perjalanan Sekolah di Kecamatan Rungkut Surabaya.

Tabel 2.

Sistem Transportasi dan Nilai LHR di Wilayah Penelitian

\begin{tabular}{lccccc}
\hline \hline Ruas Jalan & $R O W^{*}$ & Fungsi Jalan & $\begin{array}{c}\text { Tipe } \\
\text { Jalan }\end{array}$ & $\begin{array}{c}\text { Kapasitas } \\
(\mathrm{C})\end{array}$ & $\begin{array}{c}\text { LOS }^{* *} \\
(\mathrm{Q})\end{array}$ \\
\hline $\begin{array}{l}\text { J1. Rungkut } \\
\text { Puskesmas }\end{array}$ & 18,10 & $\begin{array}{c}\text { Kolektor } \\
\text { Sekunder }\end{array}$ & $4 / 2 \mathrm{D}$ & 5935,99 & 0,162 \\
$\begin{array}{l}\text { J1. Rungkut } \\
\text { Asri Utara I }\end{array}$ & 15,00 & Lokal & $2 / 2 \mathrm{UD}$ & 3107,69 & 0,104 \\
$\begin{array}{c}\text { J1. Rungkut } \\
\text { Lor IX }\end{array}$ & 9,00 & Lingkungan & $1 / 2 \mathrm{UD}$ & 2097,93 & 0,010 \\
\hline
\end{tabular}

Sumber: Survey primer 9-11 Maret 2020, pukul 06.00-08.00 dan 11.00-13.00 WIB). $R O W$ dari Data Jalan Dinas PU Bina Marga Pematusan Surabaya 2020

*ROW - Right of way.

${ }^{* *} \mathrm{LOS}-$ Level of service.

Karakteristik sistem transportasi di wilayah penelitian ini terdiri dari sistem sistem kegiatan dan sistem pergerakan. Karakteristik kecepatan rata-rata anak sekolah dasar yang berjalan kaki di wilayah penelitian ini memiliki kecepatan berjalan 1,0 meter per detik. Jarak tempuh rata-rata perjalanan anak dari rumah menuju ke sekolah di wilayah penelitian \pm 400 450 meter dengan waktu tempuh 8-10 menit untuk berjalan kaki dengan pola pergerakan seperti pada Gambar 1.

Terdapat 3 (tiga) ruas segmen pengamatan yang diteliti, yaitu pada ruas Jalan Rungkut Puskesmas, Jalan Rungkut Asri Utara I dan Jalan Rungkut Lor IX. Kondisi pergerakan lalu lintas di wilayah penelitian diketahui dengan menghitung tingkat pelayanan jalan, tipe jalan serta besar kapasitas jalan. Hasil pengamatan menunjukkan bahwa tingkat pelayanan jalan di wilayah penelitian masing-masing dalam rentang $0,00-0,20$ sehingga dapat dikategorikan dalam Tingkat Pelayanan A yang berarti keadaan arus lalu lintas dengan kecepatan kendaraan tinggi dan volume lalu lintas sekitar rendah.

B. Identifikasi dan Validasi Variabel yang Mempengaruhi Kriteria Jalur Pejalan Kaki Ramah Anak pada Rute Berbasis Footprint untuk Perjalanan Sekolah

Identifikasi dilakukan dengan analisis deskriptif kualitatif terhadap hasil kajian pustaka tentang penyediaan jalur pejalan kaki. Dengan memperhatikan kondisi eksisting di wilayah penelitian, temuan variabel hasil proses analisis deskriptif kualitatif tersebut digunakan sebagai alat validasi kepada stakeholder expert. Analisis delphi pada penelitian ini dilakukan melalui tahap eksplorasi dan dua kali iterasi. Pada tahap eksplorasi delphi menghasilkan 4 variabel baru yaitu kerb/kanstin pada indikator keselamatan, CCTV/lalu lintas cermin cembung dan tombol darurat/panic button pada indikator keamanan, serta drainase pada indikator kenyamanan. Tahap iterasi delphi pada penelitian ini mengeliminasi variabel kran siap minum pada indikator kenyamanan, sarana bermain pada indikator daya tarik dan tombol darurat/panic-button pada indikator keamanan. Temuan hasil analisis delphi pada penelitian ini yaitu terdapat 6 indikator dengan total 18 variabel kriteria jalur berjalan kaki yang aman bagi anak sekolah berbasis tapak kaki. Temuan tersebut selanjutnya disebut sebagai variabel penelitian pada Tabel 3. untuk dianalisis hingga terbentuknya menghasilkan luaran penelitian.

Tabel 3.

Indikator dan Variabel Penelitian Hasil Analisis Delphi

\begin{tabular}{|c|c|c|}
\hline Indikator & Variabel & Keterangan \\
\hline \multirow[t]{6}{*}{ Keselamatan } & $\begin{array}{l}\text { Jalur pejalan kaki/ } \\
\text { Trotoar }\end{array}$ & Konsensus $\rightarrow$ Diterima \\
\hline & $\begin{array}{l}\text { Penyeberangan pejalan } \\
\text { kaki }\end{array}$ & Konsensus $\rightarrow$ Diterima \\
\hline & $\begin{array}{c}\text { Pemisah lalu lintas } \\
\text { lokal }\end{array}$ & Konsensus $\rightarrow$ Diterima \\
\hline & Rambu lalu lintas & Konsensus $\rightarrow$ Diterima \\
\hline & $\begin{array}{c}\text { Pembatasan kecepatan } \\
\text { kendaraan }\end{array}$ & Konsensus $\rightarrow$ Diterima \\
\hline & Kerb/ Kanstin* & Konsensus $\rightarrow$ Diterima \\
\hline \multirow[t]{3}{*}{ Keamanan } & Lampu penerangan & Konsensus $\rightarrow$ Diterima \\
\hline & $\begin{array}{l}\text { CCTV/ Lalu lintas } \\
\text { cermin cembung* }\end{array}$ & Konsensus $\rightarrow$ Diterima \\
\hline & $\begin{array}{l}\text { Tombol darurat/ } \\
\text { panic-button }\end{array}$ & Tidak Konsensus $\rightarrow$ Ditolak \\
\hline \multirow[t]{5}{*}{ Kenyamanan } & Pelindung/ Peneduh & Konsensus $\rightarrow$ Diterima \\
\hline & Tempat sampah & Konsensus $\rightarrow$ Diterima \\
\hline & $\begin{array}{c}\text { Kondisi perkerasan } \\
\text { trotoar }\end{array}$ & Konsensus $\rightarrow$ Diterima \\
\hline & Kran siap minum & Tidak Konsensus $\rightarrow$ Ditolak \\
\hline & Drainase* & Konsensus $\rightarrow$ Diterima \\
\hline \multirow[t]{2}{*}{ Kemudahan } & $\begin{array}{l}\text { Lebar ruang berjalan } \\
\text { kaki }\end{array}$ & Konsensus $\rightarrow$ Diterima \\
\hline & $\begin{array}{l}\text { Keterhubungan/ } \\
\text { Konektivitas }\end{array}$ & Konsensus $\rightarrow$ Diterima \\
\hline \multirow[t]{2}{*}{ Daya Tarik } & Elemen keindahan & Konsensus $\rightarrow$ Diterima \\
\hline & Sarana bermain & Tidak Konsensus $\rightarrow$ Ditolak \\
\hline \multirow[t]{3}{*}{ Humanis } & Ubin pemandu & Konsensus $\rightarrow$ Diterima \\
\hline & Petunjuk jalan & Konsensus $\rightarrow$ Diterima \\
\hline & Jalur yang melandai & Konsensus $\rightarrow$ Diterima \\
\hline
\end{tabular}

* - Variabel baru hasil tahap eksplorasi delphi. 
C. Menilai Kepentingan dan Kinerja Jalur Pejalan Kaki Ramah Anak pada Rute Berbasis Footprint untuk Perjalanan Sekolah Berdasarkan Kondisi di Kecamatan Rungkut Surabaya

Pada penelitian ini penilaian kepentingan dan kinerja dilakukan sesuai dengan indikator keselamatan, keamanan, kenyamanan, kemudahan, daya tarik, dan humanis dengan total 18 variabel yang terdefinisikan. Setiap variabel dinilai sebagai atribut penelitian menggunakan Importance Performance Analysis (IPA). Penilaian berdasarkan preferensi pengguna jalan (pejalan kaki) yang melewati segmen penelitian di Kecamatan Rungkut Surabaya. Diagram kartesius IPA terdiri dari sumbu X (tingkat kinerja) dan sumbu Y (tingkat kepentingan). Pada diagram ini digambarkan hasil analisis kepentingan dan kinerja.

Hasil rata-rata nilai kepentingan dan kinerja variabel jalur pedestrian yang ideal berbasiskan footprint bagi anak sekolah sekitar kawasan Rungkut Surabaya menurut preferensi pengguna jalan menunjukkan adanya dominasi variabel tertinggi dan terendah. Nilai rata-rata variabel tertinggi terdapat pada tingkat kepentingan berupa lampu penerangan jalan (keamanan) dan pada tingkat kinerja berupa lampu penerangan jalan; drainase; konektivitas (kemudahan). Sedangkan nilai rata-rata variabel terendah terdapat pada tingkat kepentingan berupa elemen keindahan (daya tarik); petunjuk jalan (humanis) dan pada tingkat kinerja berupa ubin pemandu (humanis).

Hasil temuan analisis IPA menunjukkan bahwa indikator keamanan dan kenyamanan menjadi kriteria minimal yang harus disediakan menurut preferensi pejalan kaki di wilayah penelitian.

D. Merumuskan Konsep Desain Jalur Pejalan Kaki Ramah Anak pada Rute Berbasis Footprint untuk Perjalanan Sekolah di Kecamatan Rungkut Surabaya

Perumusan konsep desain merupakan tahap akhir dari penelitian ini. Analisis yang digunakan dalam merumuskan konsep adalah analisis triangulasi. Pada penelitian ini, analisis triangulasi didapat dari hasil penangkapan fenomena yang diteliti di wilayah penelitian. Untuk mengecek kebenaran, maka penggalian informasi didapatkan dari berbagai sudut pandang keilmuan. Tujuannya adalah untuk mengurangi sebanyak mungkin terjadinya bias. Sudut pandang yang digunakan dalam analisis triangulasi penelitian ini adalah menghimpun dari hasil pengamatan fenomena langsung di wilayah penelitian, hasil Importance Performance Analysis (IPA), yaitu hasil nilai tingkat kepentingan/ harapan dan kinerja variabel pembentuk kriteria jalur pejalan kaki berdasarkan preferensi pengguna jalan, dan hasil jejak pendapat stakeholders pada saat analisis Delphi.

Pedoman utama dalam perumusan konsep desain pedestrian yang ideal bagi anak ini merupakan hasil dari variabel yang disepakati stakeholders dan hasil pengelompokan variabel berdasarkan tingkat kepentingan dan harapan pengguna jalan di masing-masing ruas jalan yang menjadi wilayah penelitian. Selain itu, memperhatikan karakteristik wilayah penelitian dari hasil pengamatan fenomena di lapangan serta memperhatikan
Tabel 4.

Nilai Rata-rata Tingkat Kepentingan dan Kinerja Variabel Penelitian

\begin{tabular}{ccccccc}
\hline \hline \multirow{2}{*}{ Variabel } & \multicolumn{2}{c}{ Jalan Kolektor } & \multicolumn{2}{c}{ Jalan Lokal } & \multicolumn{2}{c}{ Jalan Lingkungan } \\
\cline { 2 - 7 } & $\overline{\boldsymbol{x}} I^{*}$ & $\overline{\boldsymbol{x}} P^{* *}$ & $\overline{\boldsymbol{x}} I^{*}$ & $\overline{\boldsymbol{x}} P^{* *}$ & $\overline{\boldsymbol{x}} I^{*}$ & $\overline{\boldsymbol{x}} P^{* *}$ \\
\hline KS1 & 4,0 & 2,2 & 4,0 & 2,6 & 4,0 & 2,2 \\
KS2 & 4,0 & 2,4 & 4,0 & 2,7 & 4,0 & 2,1 \\
KS3 & 4,2 & 2,7 & 4,2 & 3,0 & 4,2 & 2,5 \\
KS4 & 4,4 & 2,5 & 4,4 & 2,7 & 4,4 & 2,3 \\
KS5 & 4,2 & 2,3 & 4,2 & 2,6 & 4,2 & 2,2 \\
KS6 & 4,2 & 3,1 & 4,2 & 3,2 & 4,2 & 3,0 \\
KA1 & $\mathbf{4 , 5}$ & $\mathbf{3 , 1}$ & $\mathbf{4 , 5}$ & 3,5 & $\mathbf{4 , 5}$ & 2,4 \\
KA2 & 4,1 & 2,5 & 4,1 & 2,7 & 4,1 & 2,8 \\
KN1 & 3,9 & 2,8 & 3,9 & 3,2 & 3,9 & 2,3 \\
KN2 & 4,3 & 2,8 & 4,3 & 3,0 & 4,3 & 3,0 \\
KN3 & 4,2 & 2,4 & 4,2 & 3,0 & 4,2 & 2,1 \\
KN4 & 3,9 & 2,8 & 3,9 & $\mathbf{3 , 6}$ & 3,9 & 2,4 \\
KM1 & 4,2 & 2,1 & 4,2 & 2,4 & 4,2 & 2,0 \\
KM2 & 3,8 & 2,4 & 3,8 & 2,7 & 3,8 & $\mathbf{3 , 2}$ \\
DT1 & $\mathbf{3 , 7}$ & 2,1 & $\mathbf{3 , 7}$ & 2,7 & 3,7 & 2,2 \\
H1 & 4,1 & $\mathbf{1 , 6}$ & 4,1 & $\mathbf{1 , 7}$ & 3,7 & $\mathbf{1 , 4}$ \\
H2 & 3,9 & 1,7 & 3,9 & 1,8 & $\mathbf{3 , 5}$ & 1,5 \\
H3 & 4,1 & 1,8 & 4,0 & 1,7 & 3,6 & 1,5 \\
\hline \hline
\end{tabular}

(Kolektor = Ruas Jl. Rungkut Puskesmas; Lokal = Ruas Jl. Rungkut Asri Utara I; Lingkungan = Ruas Jl. Rungkut Lor IX)

Kepentingan/harapan tertinggi adalah variabel KA1 (Keamanan - Lampu penerangan) di semua ruas jalan penelitian.

Kinerja/performa tertinggi adalah variabel KA1 (Keamanan - Lampu penerangan) di ruas Jl. Rungkut Puskesmas, variabel KN4 (Kenyamanan Drainase) di ruas J1. Rungkut Asri Utara I, dan variabel KM2 (Kemudahan Konektivitas) di ruas Jl. Rungkut Lor IX.

Kepentingan/harapan terendah adalah variabel DT1 (Daya Tarik - Elemen keindahan) di ruas J1. Rungkut Puskesmas dan J1. Rungkut Asri Utara I dan variabel H2 (Humanis - Petunjuk jalan) di ruas Jl. Rungkut Lor IX.

Kinerja/performa terendah adalah variabel H1 (Humanis - Ubin pemandu/tactile) di semua ruas jalan penelitian.

* $\overline{\boldsymbol{X}}$ I - Importance Mean (Rata-rata Kepentingan)

** $\overline{\boldsymbol{X}} \boldsymbol{P}$ - Porformanco Morn (Rata-rata Kineria)

ketentuan perencanaan jalur pejalan kaki sesuai standar peraturan dan kebijakan pemerintah yang berlaku yaitu menurut [17] tentang Pedoman Perencanaan, Penyediaan, [18] tentang Perencanaan Teknis Fasilitas Pejalan Kaki dan [19] tentang Penerapan Rute Aman Selamat Sekolah (RASS). Hasil analisis triangulasi pada penelitian ini didapatkan 3 rumusan konsep desain jalur pejalan kaki ramah anak pada rute berbasis footprint untuk perjalanan sekolah di Kecamatan Rungkut diidentifikasi berdasarkan fungsi jalan. Tabel 5.

Klasifikasi Konsep Desain Jalur Pejalan Kaki Ramah Anak pada Rute Berbasis Footprint untuk Perjalanan Sekolah

\begin{tabular}{|c|c|c|c|}
\hline Klasifikasi & Konsep I & Konsep II & Konsep III \\
\hline Fungsi jalan & Kolektor & Lokal & Lingkungan \\
\hline $\begin{array}{l}\text { Lebar minimum } \\
\text { ruang bebas } \\
\text { pejalan kaki }\end{array}$ & $2,0-3,0 \mathrm{~m}$ & $1,8-2,0 \mathrm{~m}$ & $1,2-1,5 \mathrm{~m}$ \\
\hline $\begin{array}{c}\text { Lebar minimum } \\
\text { fasilitas } \\
\text { penunjang }\end{array}$ & $0,6 \mathrm{~m}$ & $0,6 \mathrm{~m}$ & $0,6 \mathrm{~m}$ \\
\hline $\begin{array}{l}\text { Atribut pelayanan } \\
\text { dengan kriteria } \\
\text { minimum }\end{array}$ & $\begin{array}{l}\text { Keselamatan } \\
\text { Keamanan } \\
\text { Kenyamanan } \\
\text { Kemudahan } \\
\text { Humanis }\end{array}$ & $\begin{array}{l}\text { Keselamatan } \\
\text { Keamanan } \\
\text { Kenyamanan } \\
\text { Kemudahan } \\
\text { Humanis } \\
\text { Daya Tarik }\end{array}$ & $\begin{array}{l}\text { Keamanan } \\
\text { Kenyamanan }\end{array}$ \\
\hline $\begin{array}{l}\text { Penggunaan lahan } \\
\text { sekitar }\end{array}$ & $\begin{array}{l}\text { Pasar,sekolah, } \\
\text { perkantoran, } \\
\text { puskesmas, } \\
\text { perumahan dan } \\
\text { permukiman }\end{array}$ & $\begin{array}{l}\text { Perumahan } \\
\text { dan } \\
\text { permukiman, } \\
\text { pertokoan, } \\
\text { kegiatan PKL. }\end{array}$ & $\begin{array}{l}\text { Perumahan } \\
\text { dan } \\
\text { permukiman, } \\
\text { sekolah dasar. }\end{array}$ \\
\hline
\end{tabular}




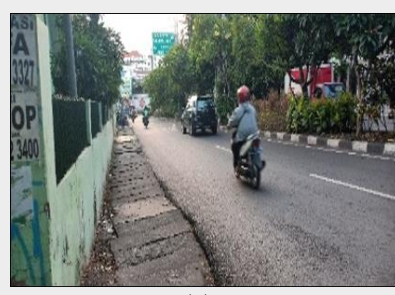

(a)

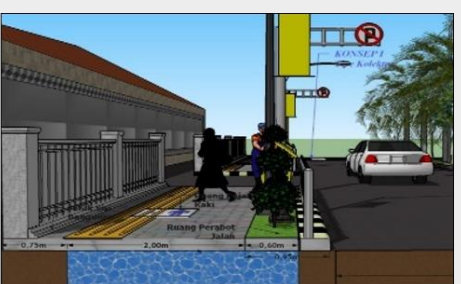

(b)
Gambar 2. Dokumentasi Eksisting (a) dan Ilustrasi Rumusan Konsep Desain I pada Fungsi Jalan Kolektor (b)

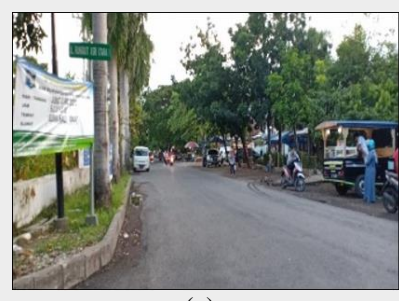

(a)

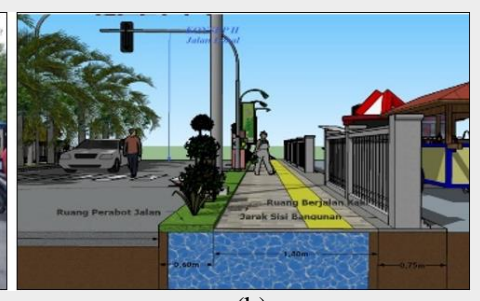

(b)
Gambar 3. Dokumentasi Eksisting (a) dan Ilustrasi Rumusan Konsep Desain II pada Fungsi Jalan Lokal (b)

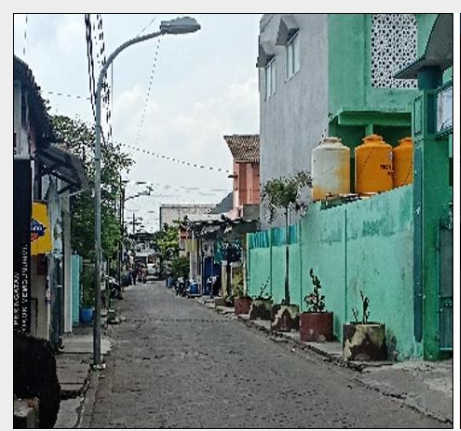

(a)

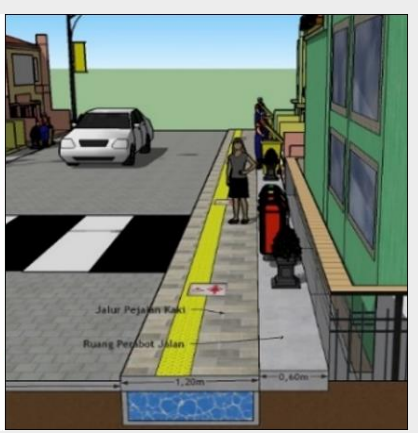

(b)
Gambar 4. Dokumentasi Eksisting (a) dan Ilustrasi Rumusan Konsep Desain III pada Fungsi Jalan Lingkungan (b)

Konsep I untuk Tipe Jalan Kolektor dengan ilustrasi terdapat pada Gambar 2. Zona yang digunakan sebagai jalur pejalan kaki pada tipe jalan kolektor terdiri dari ruang bebas jalur pejalan kaki dengan lebar minimum 2,0 - 3,0 meter dan ruang fasilitas penunjang minimum 0,6 meter dengan atribut pelayanan yang memenuhi kriteria keselamatan, keamanan, kenyamanan, kemudahan dan humanis agar semua kalangan bisa mengakses jalur pejalan kaki tersebut.

Konsep II untuk Tipe Jalan Lokal dengan ilustrasi terdapat pada Gambar 3. Zona yang digunakan sebagai jalur pejalan kaki pada tipe jalan lokal terdiri dari ruang bebas jalur pejalan kaki dengan lebar minimum 1,8-2,0 meter dan dan ruang fasilitas penunjang minimum 0,6 meter dengan atribut pelayanan yang memenuhi kriteria keselamatan, keamanan, kenyamanan, kemudahan, humanis, dan memiliki daya tarik (atraktif) untuk menarik minat dan perhatian anak serta pengguna jalan agar mau dan memilih untuk berjalan kaki.

Konsep III untuk Tipe Jalan Lingkungan dengan ilustrasi terdapat pada Gambar 4. Zona yang digunakan sebagai jalur pejalan kaki pada tipe jalan lingkungan terdiri dari ruang bebas jalur pejalan kaki yang mempunyai lebar minimum 1,2-1,5 meter dan dan ruang fasilitas penunjang minimum 0,6 meter dengan atribut pelayanan yang memenuhi kriteria keamanan dan kenyamanan. Mengingat kapasitas lalu lintas kendaraan yang sangat rendah sehingga berpotensi meningkatkan intensitas pejalan kaki yang tinggi.

\section{KESIMPULAN}

\section{A. Kesimpulan}

Hasil penelitian menunjukkan bahwa terdapat 18 variabel yang terbagi dalam 6 indikator penataan jalur pejalan kaki ramah anak pada rute berbasis footprint untuk perjalanan sekolah sebagai berikut:

1) Indikator Keselamatan, dengan variabel:
a. Jalur pejalan kaki/trotoar
b. Penyeberangan pejalan kaki
c. Peisah lalu lintas lokal
d. Rambu lalu lintas
e. Pembatasan kecepatan kendaraan
f. Kerb/kanstin

2) Indikator Keamanan, dengan variabel:

a. Lampu penerangan

b. Cctv/ Lalu lintas cermin cembung

3) Indikator Kenyamanan, dengan variabel:
a. Pelindung/peneduh
b. Tempat sampah
c. Kondisi perkerasan trotoar
d. Drainase

4) Indikator Kemudahan, dengan variabel:

a. Lebar ruang berjalan

b. Keterhubungan/konektivitas

5) Indikator Daya Tarik, dengan variabel:

a. Elemen keindahan

6) Indikator Humanis, dengan variabel:
a. Ubin pemandu
b. Petunjuk jalan
c. Jalur yang melandai

Perbedaan ketiga konsep tersebut dapat dibedakan atas fungsi jalan terkait lebar minimal ruang bebas berjalan yang wajib disediakan di tiap fungsi jalan pada rute footprint yang dilalui anak sekolah pada jalur pejalan kaki ramah anak. Persamaan ketiga konsep yaitu ketiganya memiliki atribut pelayanan minimum keamanan dan kenyamanan. Serta fungsi penggunaan lahan sekitar berupa kegiatan perumahan dan permukiman.

\section{B. Rekomendasi}

Adapun rekomendasi sebagai upaya penataan jalur pejalan kaki ramah anak di Kecamatan Rungkut tepatnya di Jalan Rungkut Puskesmas, Jalan Rungkut Asri Utara I, dan Jalan Rungkut Lor IX berdasarkan konsep desain jalur pejalan kaki ramah anak pada rute berbasis footprint untuk perjalanan sekolah adalah sebagai berikut:

1) Berdasarkan Konsep I, Tipe Jalan Kolektor untuk Jalan Rungkut Puskesmas

a. Keselamatan: Meningkatkan lebar ruang perabot jalan (utamanya penyediaan pemisah lalu lintas lokal (pagar pengaman) karena tipe jalan kolektor memiliki karakteristik lalu lintas kendaraan yang tinggi). 
b. Keamanan: Menyediakan lalu lintas cermin cembung di setiap persimpangan jalan atau menempatkan CCTV di titik-titik strategis.

c. Kenyamanan: Meningkatkan kualitas kondisi perkerasan trotoar di sepanjang ruang berjalan kaki.

d. Kemudahan: Meningkatkan lebar ruang bebas berjalan kaki dan dapat terhubung ke kegiatan guna lahan di sekitarnya.

e. Humanis: Meningkatkan penyediaan atribut kriteria humanis (ubin pemandu, ramp, petunjuk jalan) agar jalur pejalan kaki aksesibel oleh semua kalangan.

2) Berdasarkan Konsep II, Tipe Jalan Lokal untuk Jalan Rungkut Asri Utara I

a. Keselamatan: Meningkatkan keselamatan pejalan kaki dengan penyediaan fasilitas penyeberangan pejalan kaki (zebracross) dan kerb/kanstin sebagai pemisah lalu lintas lokal.

b. Keamanan: Menyediakan lalu lintas cermin cembung di setiap persimpangan jalan atau menempatkan CCTV di titik-titik strategis.

c. Kenyamanan: Meningkatkan penataan utilitas di sepanjang bahu jalan agar lebih rapi dan tertata (tidak menghalangi ruang bebas pejalan kaki).

d. Kemudahan: Meningkatkan penataan ruang bebas berjalan kaki ramah anak yang lebih tertatadan tertib.

e. Humanis: Meningkatkan penyediaan atribut kriteria humanis (ubin pemandu, ramp, petunjuk jalan) agar jalur pejalan kaki aksesibel oleh semua kalangan.

f. Daya Tarik: Memperbaiki elemen keindahan dengan memberi kesan dan desain menarik.

3) Berdasarkan Konsep III, Tipe Jalan Lingkungan untuk Jalan Rungkut Lor IX

a. Keamanan: Meningkatkan penerangan lampu jalan dan memberikan atribut pembeda antara ruang pejalan kaki dengan ruang kendaraan (bisa berupa cat jalan) agar aman.

b. Kenyamanan: Meningkatkan penyediaan rambu lalu lintas/ slogan peringatan, memberi warna pada penanda batas kecepatan kendaraan (polisi tidur) agar tidak mengganggu keselamatan pengguna jalan dan meningkatkan kebersihan lingkungan (dapat menambah elemen keindahaan agar lebih menarik).

\section{Saran}

Adapun saran setelah dilakukannya penelitian ini dengan harapan agar terdapat penelitian lanjutan sebagai pelengkap maupun penyempurna nantinya yaitu:

1. Diperlukan studi lanjutan dan komparasi konsep jalur pejalan kaki ramah anak pada rute berbasis footprint untuk perjalanan sekolah pada lokasi lain untuk mengukur akurasi hasil temuan penelitian.

2. Diperlukan definisi operasional yang spesifik yang dapat dilengkapi gambar agar responden mudah memahami maksud dan tujuan penelitian. Mengingat responden adalah anak-anak usia sekolah dasar, sehingga membutuhkan kedetailan penjelasan supaya mendapatkan data yang lebih baik.
3. Dalam menganalisis sistem kegiatan dan pergerakan pada jalur pejalan kaki, disarankan tidak menggunakan standar baku bangkitan-tarikan berdasarkan penelitian para ahli. Hal tersebut dikarenakan karakteristik pejalan kaki yang menjadi objek penelitian memiliki kemungkinan perbedaan baik secara usia, gender, kecenderungan/ kebiasaan, wilayah/negara, dan lain sebagainya. Sehingga terdapat perbedaan dengan karakteristik pejalan kaki yang menjadi objek oleh para peneliti.

\section{LAMPIRAN}

Hasil analisis tingkat penilaian kinerja dan kepentingan variabel jalur pejalan kaki ramah anak pada rute berbasis footprint digambarkan dalam kuadran sebagai berikut merupakan hasil olah software IBM SPSS Statistics 24 pada setiap kelas fungsi jalan di ruas penelitian.

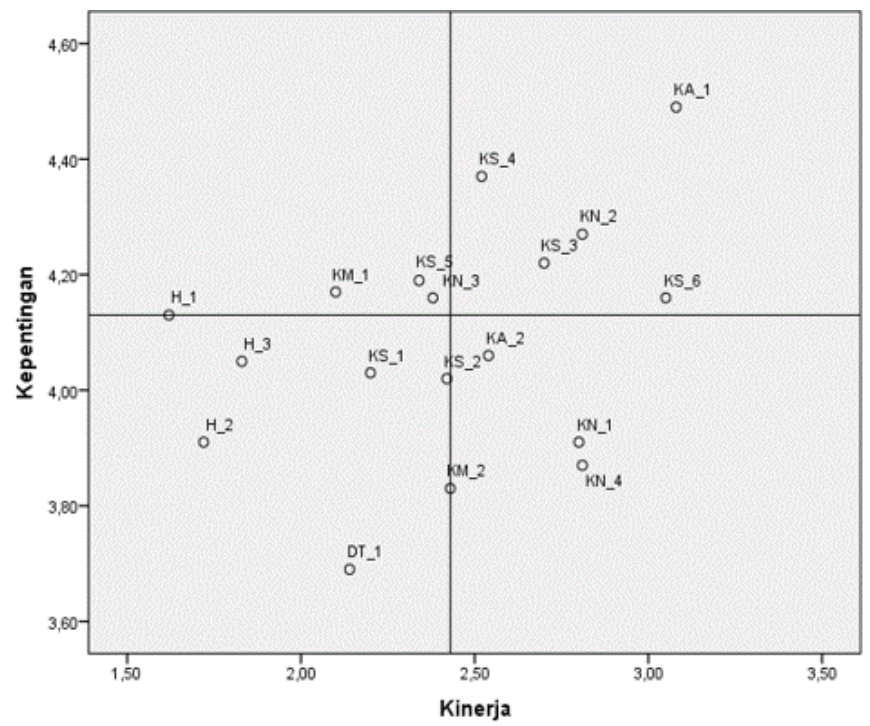

Gambar 5. Kuadran Diagram Kartesius Hasil Importance Performance Analysis (IPA) pada J1. Rungkut Puskesmas (Fungsi Jalan Kolektor)

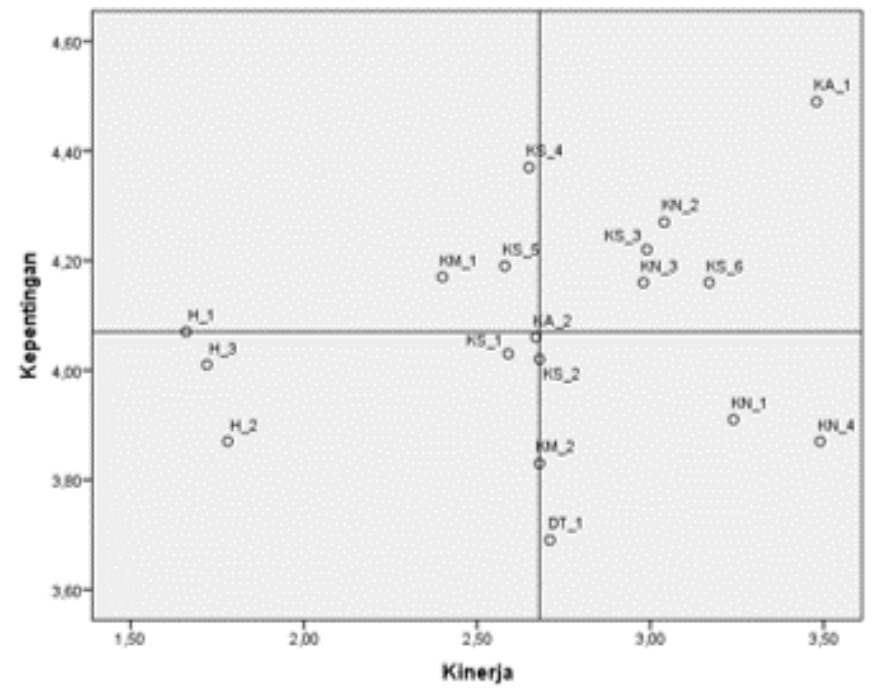

Gambar 6. Kuadran Diagram Kartesius Hasil Importance Performance Analysis (IPA) pada Jl. Rungkut Asri Utara I (Fungsi Jalan Lokal) 


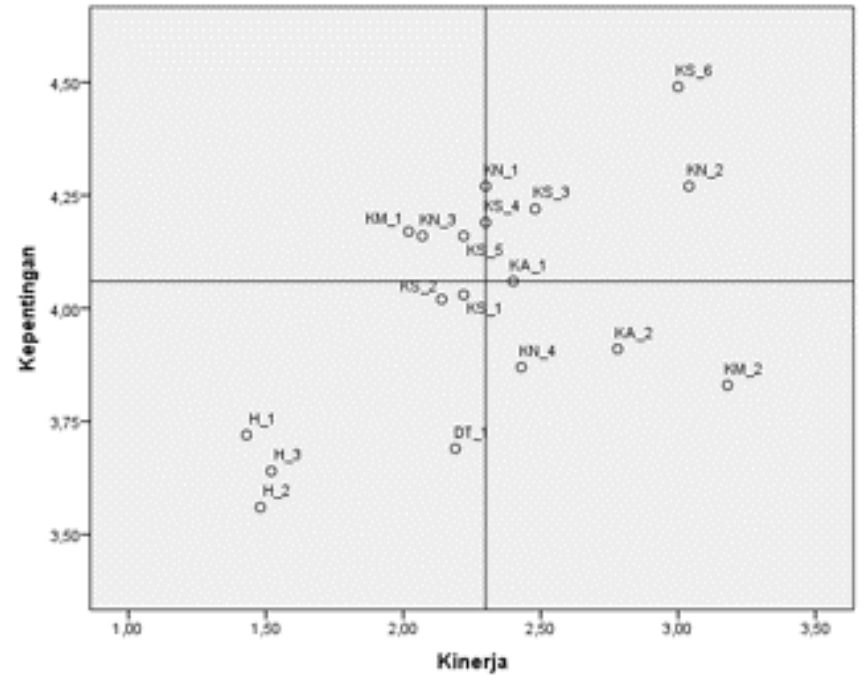

Gambar 7. Kuadran Diagram Kartesius Hasil Importance Performance Analysis (IPA) pada Jl. Rungkut Lor IX (Fungsi Jalan Lingkungan)

\section{UCAPAN TERIMA KASIH}

Puji syukur kehadirat Allah SWT. atas limpahan rahmat-Nya sehingga penulis dapat menyelesaikan penelitian ini dengan baik. Penulis mengucapkan terima kasih kepada Direktorat Pendidikan Tinggi, Departemen Pendidikan dan Kebudayaan Republik Indonesia atas dukungan finansial

melalui Beasiswa Bidik Misi tahun 2017-2018 dan kepada PT. Lautan Luas Tbk. atas dukungan finansial melalui Beasiswa Pendidikan tahun 2019-2020, serta semua responden yang banyak memberikan data selama penelitian.

\section{DAFTAR PUSTAKA}

[1] I. Rumtianing, "Kota layak anak dalam perspektif perlindungan anak," J. Ilm. Pendidik. Pancasila dan Kewarganegaraan, vol. 27, no. 1, pp. 723, 2016.

[2] Fatimah and Nuryaningsih, Buku Ajar Buku Ajar. 2018.

[3] ITDP, "Jakarta NMT Vision and Design Guideline," 2017.

[4] M. Anwari, "Global Status Report on Road Safety" ISBN 978-92-4156568-4 WHO. no. September. 2018.

[5] Korlantas, "Implementasi Road Safety Menuju Zero Accident," 2018.

[6] P. K. Surabaya, "Evaluasi kota layak anak 2019 best practice," 2019.

[7] Y. Shi and L. Fei, "Study on the design of urban public space in city complex," Adv. Mater. Res., vol. 671-674, pp. 2496-2499, 2013.

[8] M. Andreou, "Planning for Pedestrian Safety around Schools," p. 96, 2010.

[9] E. F. Rini, R. A. Putri, Mulyanto, and N. Handayani, "The ecological impacts of primary education facilities based on a child-friendly neighborhood unit criteria in Surakarta," IOP Conf. Ser. Earth Environ. Sci., vol. 129, no. 1, 2018.

[10] S. Imtiyas, R. A. Putri, and E. F. Rini, "Faktor-faktor yang Mempengaruhi Pemilihan Moda Bermotor Anak dalam Mengakses Sekolah Dasar di Kota Surakarta," Reg. J. Pembang. Wil. dan Perenc. Partisipatif, vol. 14, no. 1, p. 13, 2019.

[11] M. MAHARDDHIKA, "Setting Group Pkl Di Kawasan Terminal Blok M," 2007.

[12] H. Permana, 2017 Pelatihan Perkusi Melalui Metode Rhythm Syllables Pada Ekstrakurikuler Marching Band Di SMKN 6 Bandung Universitas Pendidikan Indonesia | repository.upi.edu | perpustakaan.upi.edu," no. 1998, pp. 41-54, 2017.

[13] M. B. Nugroho, J. Chem. Inf. Model., vol. 53, no. 9, pp. 1689-1699, 2013.

[14] WHO, "Keselamatan Pejalan kaki Manual keselamatan jalan," Who, pp. $5-7,2013$.
[15] J. K. M. Sirait, P. D. R. Naibaho, and E. R. Aritonang, "Kajian Tentang Jalur Pedestrian Berdasarkan Aspek Kenyamanan," J. Arsit. ALUR, vol. 1, no. 2, pp. 11-21, 2018.

[16] S. N. Indonesia and B. S. Nasional, "Tata cara perencanaan lingkungan perumahan di perkotaan," 2004.

[17] Kementrian Pekerjaan Umum, "Lampiran Pedoman perencanaan, Penyediaan dan Pemanfaatan Prasarana dan Sarana Jaringan Pejalan Kaki di Kawasan Perkotaan, Kementrian Pekerjaan Umum, 2014," vol. 2013, no. No. 03/PRT/M/2014, 2014.

[18] D. A. N. P. Rakyat, "Perencanaan teknis fasilitas pejalan kaki Kementerian Pekerjaan Umum Dan Perumahan Rakyat," 2018.

[19] Yuliana, "Perancangan Jalur Pedestrian," 2016. 